\title{
Simulation and Experimental Research on Vibration and Noise of Transmission
}

\author{
Yulong Lei ${ }^{1}$, Bo Yan ${ }^{1}$, Yao Fu ${ }^{1}$, Liu Zongsheng ${ }^{2}$, Chen Wei ${ }^{1}$ \& Hou Liguo ${ }^{1}$ \\ 1.Jilin University, State Key Laboratory of Automobile Simulation and Control, Changchun 130022; \\ 2. Technical Center of Dongfeng Commercial Vehicle Company Limited, Wuhan 430000
}

Keywords: transmission; vibration and noise; simulation; experimental

Abstract. To solve the problem of vibration and noise of transmission, the finite element model and boundary element model of transmission case were established to modal analysis, vibration response analysis and radiated noise analysis and prediction. The characteristics of vibration and radiation noise of transmission case were simulated by the finite element method combined with boundary element method. The constant mesh gear pair and a box body resonance were the noise source of transmission was determined through the noise and vibration bench test. The scheme of gear modification was presented in order to achieve the purpose of reducing noise of transmission.

\section{Introduction}

With a four-speed automatic mechanical transmission of a type of electric bus, this paper utilizes finite element combined with boundary element model for the transmission system under the excitation of gearbox vibration and noise. The noise is identified by vibration test, the improvement is proposed to reduce the noise of the transmission. Organization of the Text.

\section{Analysis of gearbox body vibration and noise simulation}

The process of vibration and noise simulation is shown in Fig.1.

\section{Model analysis of the body}

Import the 3D model into Hypermesh, and the tetrahedral element was used for meshing. The finite element model and orientation definition of the box under free mode are shown in Figure 2.
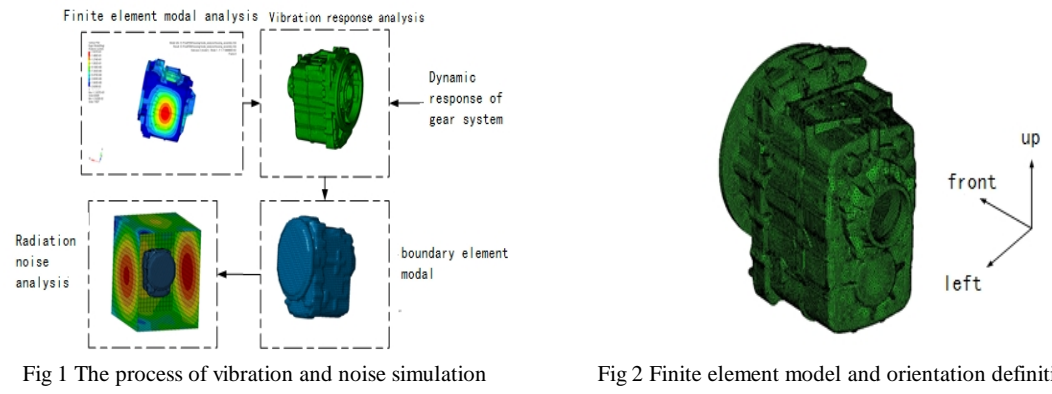

Fig 2 Finite element model and orientation definition of the body

Noise analysis of the transmission was done, take the first-ten-step frequencies, the vibration mode is shown in Figure 3, and the modal contrast analysis is shown in Table 1.

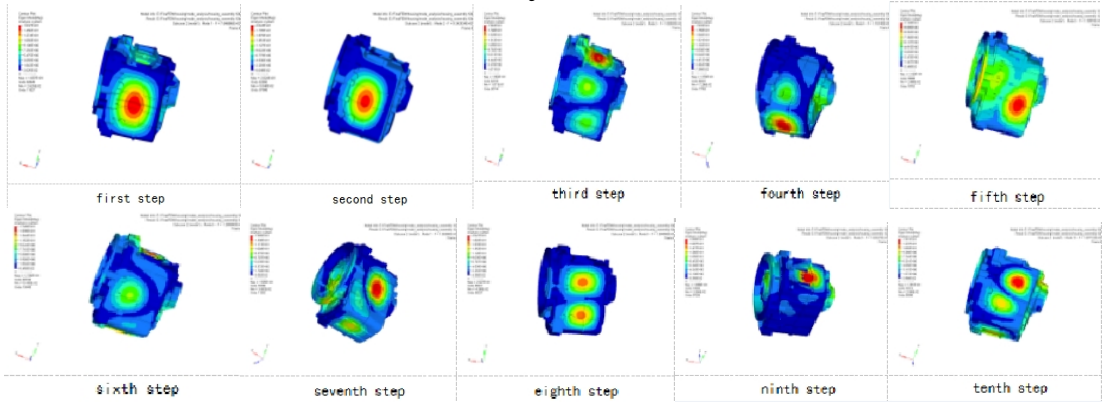

Fig 3 the first-ten-step frequencies of the body 
Table 1, Analysis of the first-ten-step frequencies

\begin{tabular}{|c|c|l|}
\hline Modal & Frequency(Hz) & \multicolumn{1}{|c|}{ Modal shape } \\
\hline first & 754.7 & Bending vibration, The displacement of the middle position on two sides of the box body is larger. \\
\hline second & 934.3 & $\begin{array}{l}\text { Bending vibration, The displacement of the middle position on two sides of the box body is larger. } \\
\text { Contrary to the vibration direction of the first mode. }\end{array}$ \\
\hline third & 1082.6 & On the side of the box body displacement is large \\
\hline fourth & 1118.1 & The lower side of the box vibration displacement is larger \\
\hline fifth & 1159.9 & Box body's left and right vibration displacement is larger \\
\hline sixth & 1285.9 & The upper and lower sides of the box vibration displacement is larger \\
\hline $\begin{array}{c}\text { sevent } \\
\text { h }\end{array}$ & 1363.6 & Box body's left and right vibration displacement is larger \\
\hline eighth & 1384.1 & $\begin{array}{l}\text { Bending vibration, The vibration displacement near and below the box body is larger and the vibration } \\
\text { direction is opposite. }\end{array}$ \\
\hline ninth & 1526.3 & The local vibration on the side of the box \\
\hline tenth & 1597.7 & Torsional vibration \\
\hline
\end{tabular}

The left and right sides, upper and lower sides of the body are weak parts, by improving the structure of the body, the natural frequency of the gearbox can be avoided as far as possible to the frequency range of the transmission.

\section{Analysis of the transmission-body-surface vibration simulation}

The body's finite element model was imported into LMS.Virtual.Lab, the material properties and boundary conditions of gearbox were defined, and the Nastran solver was used to solve the transmission constraint mode. The vibration response signal of the bearing seat was taken as the excitation of the box vibration response analysis, and the vibration response was analyzed in LMS.Virtual.Lab .

\section{Transmission noise prediction based on acoustic boundary element method}

The finite element model of transmission box structure was imported into LMS Virtual. Lab software, and established the boundary element model of transmission, shown in Fig 4.

By setting the point grid in the sound field to view the specified location in LMS Virtual. Lab, shown in Fig 5.

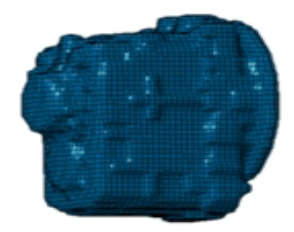

Fig 4 boundary element model of the body

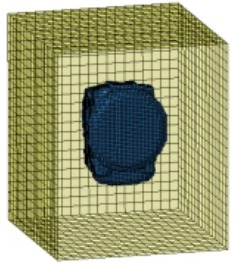

Fig 5 The grid point model

Mostly,the radiation noise of the left and right sides of the box is larger, and the radiated noise of the upper and lower sides of the box is also higher. The radiated noise of transmission is affected by the vibration characteristics of the gear system and the inherent characteristics of the body.

\section{Transmission vibration and noise test}

This experiment analysed the overall noise level of the transmission, to study the noise effect of different conditions on the transmission, vibration and noise processing of bench test data, according to the source of spectrum analysis and order analysis method to identify the transmission of vibration and noise.

\section{Transmission vibration noise bench test}

The experiment was carried out in the semi anechoic room, which consisted of input motor, measured transmission, output shaft, rear axle, speed up box and load motor.

\section{Analysis of the transmission-noise-test results}

Record the maximum value of the noise during the test.According to the results of transmission noise test, the noise level of transmission was analyzed, and the radiation noise characteristics of gearbox were studied. 
Change the input speed of the transmission, record the noise data of three measuring points, and test results of 1 test point is shown in Fig 6.

The noise test results of each block increase with the increase of rotating speed, and with the increase of the gear position, the noise is bigger, and the fourth gear noise is the largest at the same speed.

The test results in this paper are only the third gear for different measuring positions and different input torque, the no-load noise test results and the input torque to the noise test of $400 \mathrm{Nm}$ three measuring points of the results are shown in Figure7 and Figure 8.

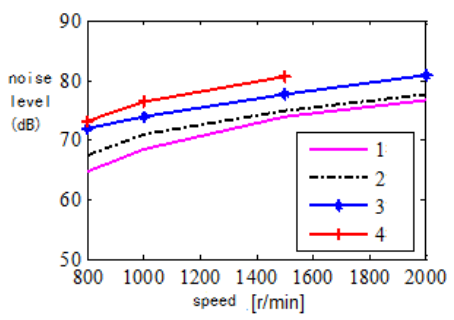

Fig 6 Comparison of noise in each gear

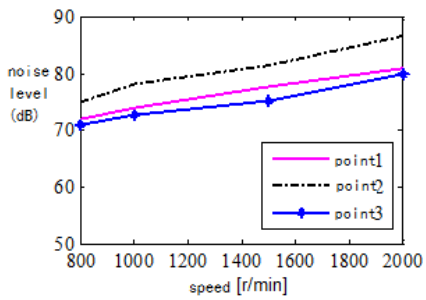

Fig 7 noise change with speed at no-load

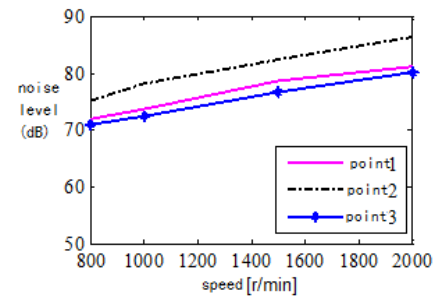

Fig 8 noise with speed in $400 \mathrm{Nm}$

With the increase of speed, the noise test results of each measuring point increases gradually, and the 2 sound level meter results were larger than the other two points, 3 sound level meter results measured minimum radiation noise of gearbox which is less than the left and right sides of the radiation noise. The input torque has little effect on the transmission noise test results.

\section{Analysis of the test results and identification of vibration and noise sources}

Take lifting speed test for each gearbox under different input torque, The transmission constant mesh gear pair is 24 order, the order of the amplitude of acceleration is three times and four times of the constant gear, it can be preliminarily determined that the acceleration caused by the constant mesh gear is higher.

The output-shaft-bearing-seat acceleration sensor collected $\mathrm{Y}$ direction acceleration amplitude under $400 \mathrm{Nm}$ is shown in Figure 9.

According to the analysis of the vibration and noise test results, it can be seen that the main reasons of the excessive noise of the transmission are the following two: the meshing vibration and the resonance of the body.

Input torque was $400 \mathrm{Nm}$, input speed was $1500 \mathrm{r} / \mathrm{min}$, the output shaft bearing seat near the body surface node vibration simulation results (shown in Figure 10) and test results were compared.The simulation results show that the frequency of acceleration peak coincides with the experimental results, which verifies the correctness of the vibration simulation analysis method.

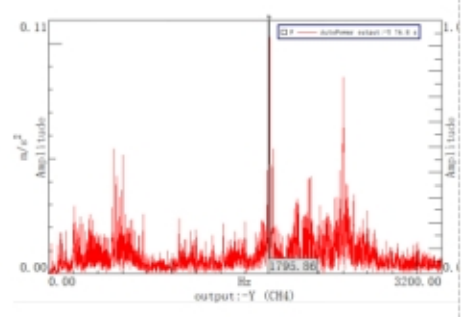

Fig 9 Acceleration spectrum on Y direction under 400Nm

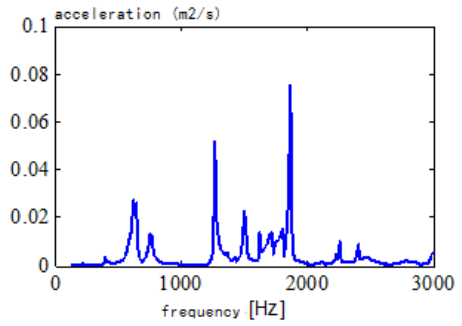

Fig 10 Variation of noise with speed in $400 \mathrm{Nm}$

\section{Study on vibration and noise reduction of transmission}

This paper improves the gear transmission system by means of gear modification, so as to improve the whole noise level of the transmission. The gear after modification is shown in Fig 11. 


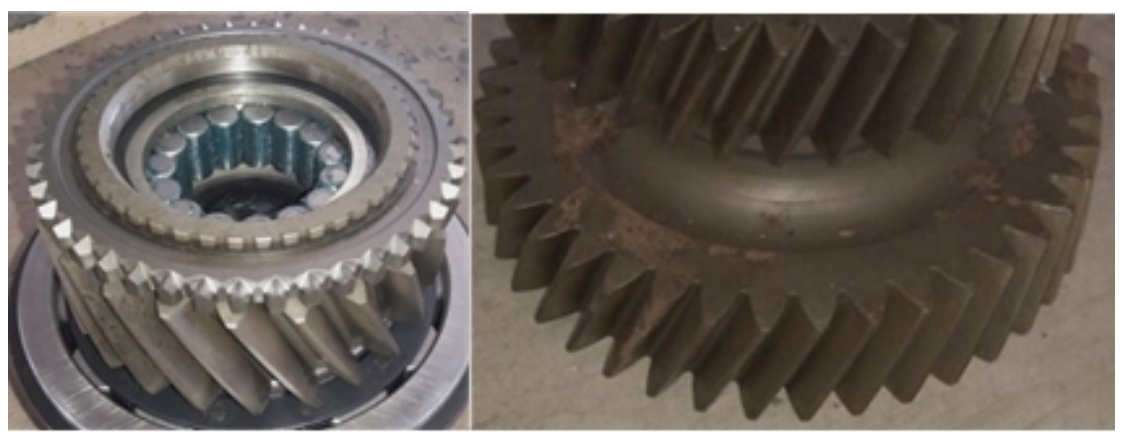

Fig 11 constant-meshing-gear-pair practicality picture after modification

As shown in Fig 12-15, after modification, the noise of each gear is reduced in different degrees.

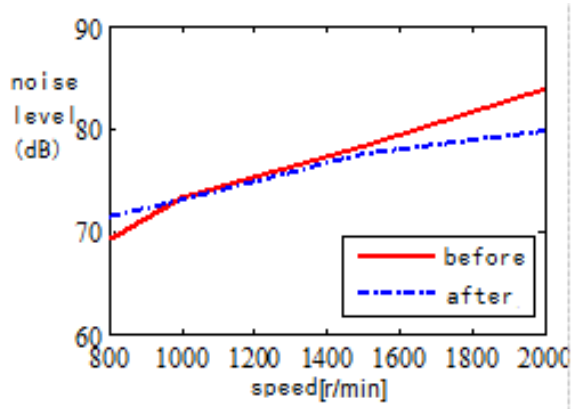

Fig 12 Noise contrast before and after improvement of first

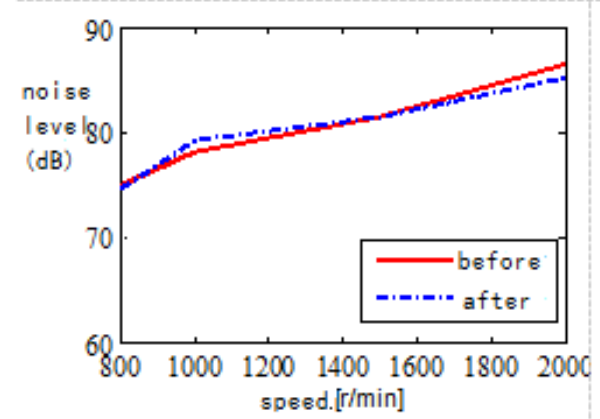

Fig 14 Noise contrast before and after improvement of third

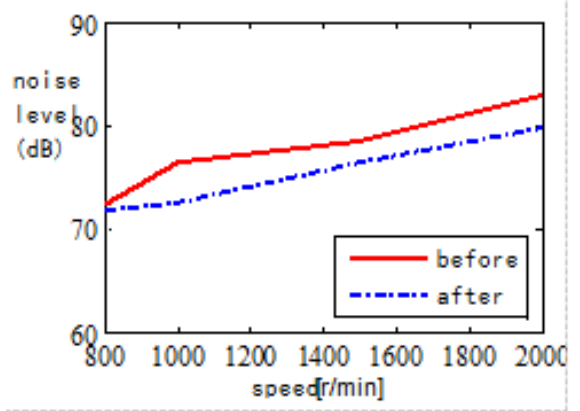

Fig 13 Noise contrast before and after improvement of second

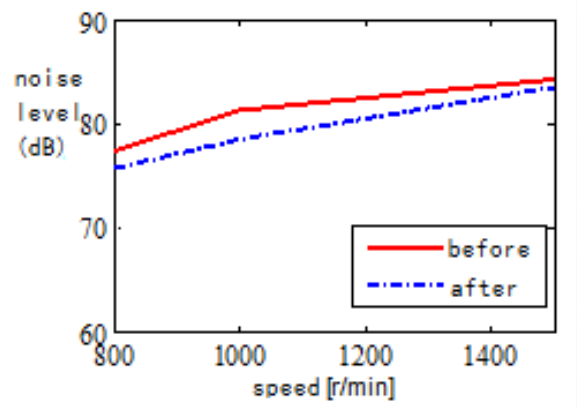

Fig 15 Noise contrast before and after improvement of fourth

\section{Conclusions}

Research on mechanical automatic transmission of electric bus, and The vibration and noise characteristics of transmission are simulated by finite element method and boundary element method, The results show that the noise is radiated from the left and right sides of the body, The position of the radiation noise is related to the position of the body's natural vibration mode, The natural vibration mode of the body has a great influence on the radiation noise characteristics of the transmission. The vibration and noise sources of the transmission are resonance of constant meshing gear pair and body identified by the vibration noise test, a scheme for modification of continuously meshing gear pair is put forward, and the test of the gearbox after modification shows that the improved scheme can effectively reduce the transmission noise.

\section{Acknowledgments}

This work was supported by International S\&T Cooperation Program of China ( Grant No. 2014DFA71790 ), the Key Scientific and Technological Project of Jilin Province (Grant No. 20160519008JH ) ,Chinese National Natural Science Foundation(Grant No. 51575220) and Graduate Innovation Fund of Jilin University ( Grant No. 2016170 ) " . 


\section{References}

[1] Yong Cao.Analysis and Control of electric vehicle interior noise[D].Wuhan University of Technology,2011,In Chinese.

[2] Marco Zanussi Barreto, Edson Duque. Operational Vibration Analysis of Automotive Transmissions[C]. 2011 SAE paper, 2011-01-0147.

[3] Won Shin, Ashish Kanase, Sungwook Hwang, Sangbum Baek, Hyutae Shim, Seiwoong Oh. 6 Speed Automatic Transmission Vibration Magnitude Prediction and Whine Noise Improvement through Transmission System Modeling [C]. 2011 SAE paper, 2011-01-1553.

[4] Amit J Bora, Robert White, Dalsang Chaudhari. Gear Rattle Noise Prediction from Dynamic Simulation[C]. 2011 SAE paper, 2011-01-2242.

[5] Ashish Kanase, Yogiraj Mane, Amey Kulkarni. Manual Gearbox Gear Whine Noise Prediction and Importance of Parametric Sensitivity in NVH[C]. 2013 SAE paper, 2013-26-0091.

[6] Yi Guo, Tugan Eritenel, Tristan M. Ericson, Robert G. Parker. Vibro -acoustic propagation of gear dynamics in a gear -bearing -housing system[J]. Journal of Sound and Vibration, 333(2014) 5762-5785.

[7]Jeffrey A. Morgan, Maruthi R. Dhulipudi, Refaat Y. Yakoub, Alan D. Lewis. Gear Mesh Excitation Models for Assessing Gear Rattle and Gear Whine of Torque Transmission Systems with Planetary Gear Sets[C]. 2007 SAE paper, 2007-01-2245.

[8] Zhaohui Sun, Glen Steyer, Jason Ley. Geartrain Noise Optimization in an Electrical Drive Unit[C]. 2015 SAE paper, 2015-01-2365.

[9] Masao Nakagawa, Mohamed Ali Ben Abbes, Toshiki Hirogaki, Eiichi Aoyama. Investigation of Characteristics of Gear Meshing Noise under Three-Axis Driving Planetary Gear Set[C]. SAE Int. J. Passeng. Cars - Mech. Syst. 9(1):2016.

[10] Quan Shi, Dong Guo, Xiaohui Shi, Peng Yi , Research on noise source location of transmission based on microphone array[J], Vibration and Impact,2012,13;134-137,In Chinese.

[11] Jinchao Li, Noise analysis and control of automotive transmission[D],Chongqing University,2012, In Chinese. 